\title{
Incidentally Found Mucosal Nodularity on the Second Portion of Duodenum
}

\section{Joo Hyun Lim}

Department of Internal Medicine, Healthcare Research Institute, Seoul National University Hospital Healthcare System Gangnam Center, Seoul, Korea

Question: A 40-year old man presented with duodenal mucosal nodularity incidentally found in a screening esophagogastroduodenoscopy (EGD). He did not have any abnormal symptoms nor recent weight loss. He was taking medicine for hypertension and dyslipidemia since 1 year ago and was non-smoker and social drinker. His laboratory findings were all within normal limit. On EGD, nonspecific slightly pale grayish mucosal nodularity was found on the second portion of duodenum, around the ampulla of Vater and in about 1 2 $\mathrm{cm}$ distal area from the ampulla (Fig. 1A, B). Colonoscopy and abdomino-pelvic CT scan revealed no abnormal findings.

What is the most likely diagnosis?
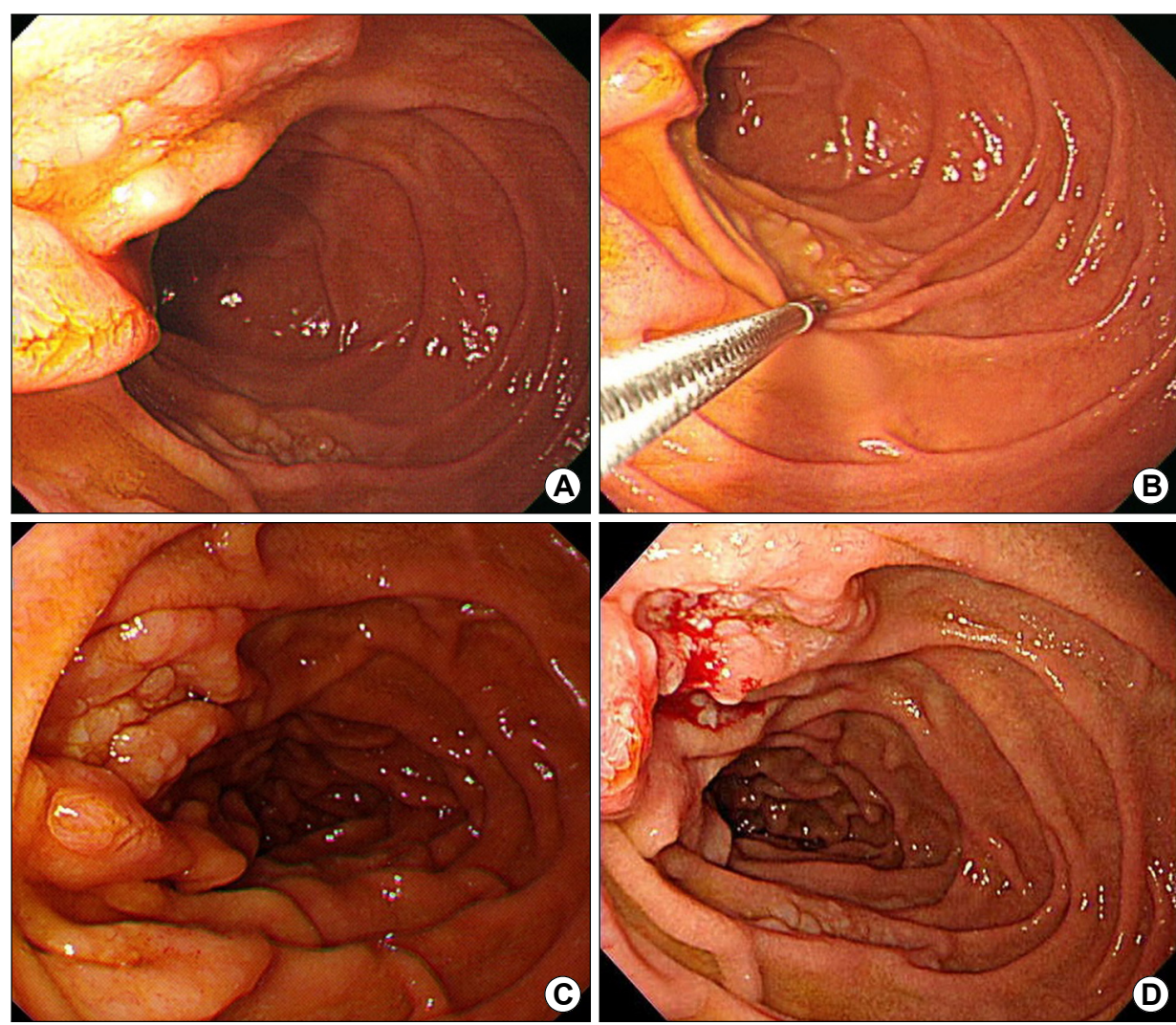

Fig. 1. Endoscopic findings. (A) Mucosal nodularity is visible around the ampulla of Vater in a slightly distal area of the second portion of the duodenum. (B) Clustered follicular nodules near the ampulla of Vater are clearly visible. (C) A prominent whitish nodularity is observed over the ampulla of Vater. (D) Biopsy examination was performed at the prominent nuduarity over the amc

Received: October 8, 2021 Revised: November 6, 2021 Accepted: November 9, 2021

Corresponding author: Joo Hyun Lim

Department of Internal Medicine, Healthcare Research Institute, Seoul National University Hospital Healthcare System Gangnam Center, 152 Teheran-ro, Gangnam-gu, Seoul 06236, Korea Tel: +82-2-2112-5807, Fax: +82-2-2112-5635, E-mail: joohyunlim@snuh.org

Copyright $\odot 2022$ Korean College of Helicobacter and Upper Gastrointestinal Research

@ The Korean Journal of Helicobacter and Upper Gastrointestinal Research is an Open-Access Journal. All articles are distributed under the terms of the Creative Commons Attribution Non-Commercial License (http:// creativecommons.org/licenses/by-nc/4.0) which permits unrestricted non-commercial use, distribution, and reproduction in any medium, provided the original work is properly cited. 

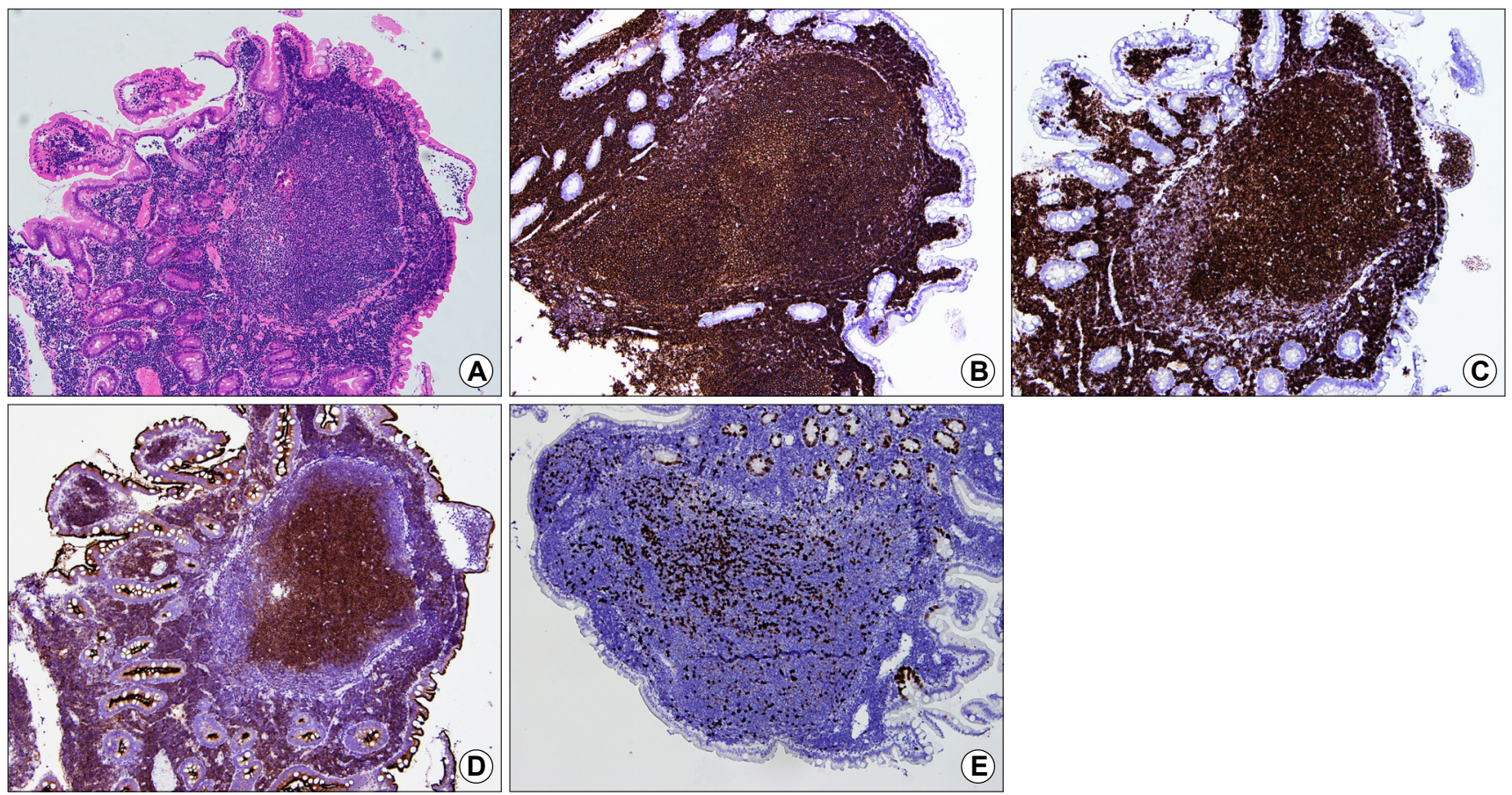

Fig. 2. Pathologic features of the duodenal mucosal nodularity. (A) Dense lymphoid cell infiltration in the lamina propria with follicle formation is seen on hematoxylin and eosin staining $(\mathrm{H} \& \mathrm{E}, \times 100)$. (B) CD20 positivity (IHC, $\times 100)$. (C) Bcl-2 positivity (IHC, $\times 100)$. (D) CD10 positivity (IHC, $\times 100)$. (E) Ki-67 positivity (5\%) (IHC, $\times 100)$.

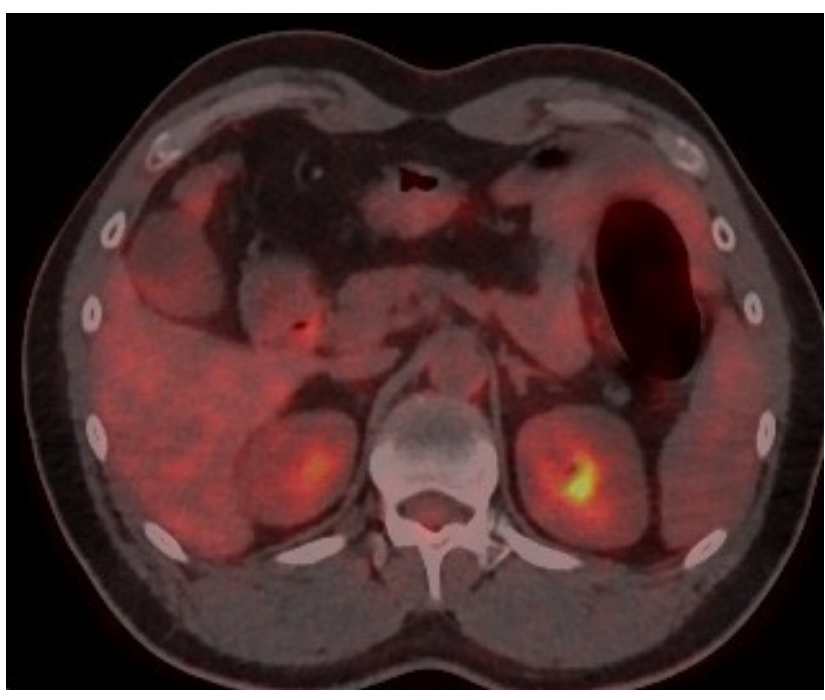

Fig. 3. Mild hypermetabolic activity is visible in the duodenum.

Answer: Urea breath test showed negative result. In the follow-up EGD, diffuse mucosal nodularity around the ampulla of Vater was shown in the second portion of duodenum (Fig. 1C). Biopsy revealed dense infiltration of lymphoid cells in the lamina propria, forming follicles (Fig. 2). As this finding was highly suggestive of malignant lymphoma, immunohistochemistry was performed and showed CD20, CD10, and B-cell lymphoma 2 (BCL-2) positive, CD3/CD5 negative, and Ki-67 positive in 5\%.

This finding was consistent with grade 1 to 2 follicular lymphoma. Therefore, whole body positron emission tomography scan was performed for staging, and it revealed mild hypermetabolic lesion in duodenum (Fig. 3). Bone marrow examination was performed and it was normal. His modified Ann Arbor stage was determined as IE1. After discussion with oncology professional, he was decided to be observed without treatment. Six months later, follow-up EGD revealed no interval change and biopsy was performed at the periampullary nodularity (Fig. 1D), which revealed the same result as previous one. $\mathrm{He}$ is under follow-up without any symptoms.

Primary gastrointestinal follicular lymphoma is a rather rare disease, although the gastrointestinal tract is the most common site of extranodal lymphoma. ${ }^{1}$ Although rare, when follicular lymphoma involves the gastrointestinal tract, the duodenum is the most commonly affected site. Most of the cases of duodenal follicular lymphoma are asymptomatic and its specific risk factors are 
unknown. ${ }^{2}$ Unlike non-gastrointestinal follicular lymphoma, primary gastrointestinal follicular lymphoma shows remarkably indolent behavior. It shares some features with mucosa-associated lymphoid tissue (MALT) Iymphoma. However unlike MALT Iymphoma, duodenal follicular lymphoma does not show marginal zone differentiation. Also MALT lymphoma is often negative for CD10 because of its origin from post-germinal center memory B cells. ${ }^{3}$

Old studies have suggested local radiation therapy for limited stage follicular lymphoma, however Stanford University first advocated watch-and-wait strategy according to the result of their two retrospective studies. ${ }^{4,5} \mathrm{~A}$ retrospective study including 63 cases of duodenal follicular lymphoma reported good prognosis after heterogeneous treatments including watch-and-wait, radiation, Rituximab, and chemotherapy. ${ }^{6}$ Among them seven patients reached complete remission without treatment. In 2016, World Health Organization recognized this entity as one distinct form of duodenal type follicular lymphoma. ${ }^{7}$ However, there is still no established consensus on the initial treatment modality. ${ }^{8}$ Most oncologists either take a "watch-and-wait" strategy, or some treat with local radiation. More recently, some tried rituximab or even chemotherapy. However, for asymptomatic, low grade, limited stage duodenal follicular lymphoma, chemotherapy is generally not recommended and watch-and-wait can be a good option. ${ }^{3}$

\section{CONFLICT OF INTEREST}

No potential conflict of interest relevant to this article was reported.

\section{ORCID}

Joo Hyun Lim ～(D) https://orcid.org/0000-0002-8437-096X

\section{REFERENCES}

1. Graham RL, Mardones MA, Krause JR. Primary follicular lymphoma of the duodenum. Proc (Bayl Univ Med Cent) 2015;28: 381-383.

2. Misdraji J, Harris NL, Hasserjian RP, Lauwers GY, Ferry JA. Primary follicular lymphoma of the gastrointestinal tract. Am J Surg Pathol 2011;35:1255-1263.

3. Marks E, Shi Y. Duodenal-type follicular lymphoma: a clinicopathologic review. Arch Pathol Lab Med 2018;142:542-547.

4. Portlock CS, Rosenberg SA. No initial therapy for stage III and IV non-Hodgkin's lymphomas of favorable histologic types. Ann Intern Med 1979;90:10-13.

5. Horning SJ, Rosenberg SA. The natural history of initially untreated low-grade non-Hodgkin's lymphomas. N Engl J Med 1984;311:1471-1475.

6. Schmatz AI, Streubel B, Kretschmer-Chott E, et al. Primary follicular lymphoma of the duodenum is a distinct mucosal/submucosal variant of follicular lymphoma: a retrospective study of 63 cases. J Clin Oncol 2011;29:1445-1451.

7. Swerdlow SH, Campo E, Pileri SA, et al. The 2016 revision of the World Health Organization classification of lymphoid neoplasms. Blood 2016;127:2375-2390.

8. Lee H, Oh D, Yang K, et al. Radiation therapy outcome and clinical features of duodenal-type follicular lymphoma. Cancer Res Treat 2019;51:547-555. 